\title{
An Improved Three-Phase Buck Rectifier Topology with Reduced Voltage Stress on Transistors
}

\author{
Jiaxing Lei, Member, IEEE, Shuang Feng, Jianfeng Zhao, Wu Chen, Senior Member, IEEE, \\ Patrick Wheeler, Senior Member, IEEE, Mingming Shi
}

\begin{abstract}
The three-phase buck rectifier (3ph-BR) is suitable for applications where a voltage step down function is required. In this paper, an improved $3 \mathrm{ph}-\mathrm{BR}$ topology is proposed to reduce the voltage stress on the transistors. The freewheeling diode in the conventional topology is split into two diodes in series and the input neutral point is connected to the common point of the two diodes. With the proposed topology and the correspondingly modified modulation scheme, the transistors only need to withstand the input phase voltage instead of the line-to-line voltage, bringing about the significant reduction of voltage stress. The proposed topology enables a more cost-efficient and flexible selection of the transistors. Experimental results have verified the validity of the modified topology and associated modulation scheme.
\end{abstract}

\section{INTRODUCTION}

${ }^{1}$ The three-phase buck rectifier (3ph-BR), featuring wide control range of output voltage, small input filter, and intrinsic capability to limit the start-up inrush current, is suitable for applications which require a voltage step down function from an AC source to a DC output [1]-[3]. The topology has attracted a lot of attentions for telecom power supplies and the electric vehicle chargers.

The conventional 3ph-BR topology is shown in Fig. 1, which consists of three legs and one freewheeling diode. Each leg includes two transistors (MOSFETs or IGBTs) and two diodes in series. Alternatively, one transistor and four diodes can be used in each leg, forming the topology of three-switch 3ph-BR [5]. The modulation and control technique of the $3 \mathrm{ph}-\mathrm{BR}$ is well developed [1]-[2], [7]-[8]. In recent years, researchers have tried to improve the practical performance [4]-[5],

${ }^{1}$ Manuscript received March 03, 2019; revised May 03, 2019; accepted July 26, 2019. Date of publication xx xx, 2019; date of current version xx xx, 2019. This work was supported in part by the National Natural Science Foundation of China under Grant 51807025 and in part by the Natural Science Foundation of Jiangsu Province of China under Grant BK20180396. Recommended for publication by Associate Editor xx xx. (Corresponding author: Shuang Feng.)

J. Lei, S. Feng, J. Zhao, W. Chen are with the School of Electrical Engineering and with the Jiangsu Provincial Key Laboratory of Smart Grid Technology and Equipment, Southeast University, Nanjing 210096, China, Southeast University, Nanjing 210096, China. (e-mail: jxlei@seu.edu.cn, sfeng@seu.edu.cn, jianfeng_zhao@seu.edu.cn, chenwu@seu.edu.cn)

P. Wheeler is with the Department of Electrical and Electronics Engineering, University of Nottingham, Nottingham NG7 2RD, U.K. (e-mail: pat.wheeler@nottingham.ac.uk)

M. Shi is with the State Grid Jiangsu Electric Power Research Institute of State Grid Jiangsu Electric Power Co., Ltd, Nanjing 211103, China (e-mail: simon8612@163.com).

Color versions of one or more of the figures in this paper are available online at http://ieeexplore.ieee.org.

Digital Object Identifier xxxxxxxxxxx.

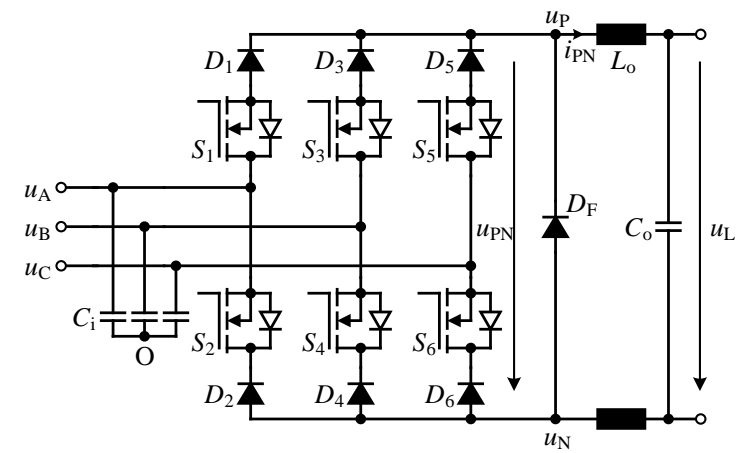

Fig. 1 Conventional topology of three-phase buck rectifier

[9]-[12], especially the efficiency. For example in [4], a 98.8\% efficient $5-\mathrm{kW} 3$ ph-BR was realized by paralleling devices. Accurate expressions for loss calculations are presented in [5], which are useful guidelines for hardware design. In [10], a prototype using silicon carbide ( $\mathrm{SiC}$ ) devices was designed, achieving efficiency higher than $98.5 \%$ at $7.5 \mathrm{~kW}$. In [11], different device combinations were considered to improve the efficiency. In [12], a 3ph-BR topology with delta-type input connection was explored to reduce the conduction losses.

The understanding of the efficiency of the $3 \mathrm{ph}-\mathrm{BR}$ is therefore good, yet less attention has been paid to the voltage stress on devices. It is generally thought that all the devices need to withstand the line-to-line input voltage [5], and the voltage rating must be selected accordingly. For a $380 \mathrm{~V}$ utility grid input, the maximum voltage stress is about $540 \mathrm{~V}$. Considering a typical margin (around 50\%), voltage rating of devices must be at least $900 \mathrm{~V}$ or higher. This leads to a problem of device selection. Silicon (Si) MOSFETs have good performance but their voltage ratings are usually less than $650 \mathrm{~V}$ (except the CoolMos [13]). IGBTs can easily achieve higher voltage rating (upwards of $1200 \mathrm{~V}$ ), but their switching performance is poorer and devices cannot be paralleled to improve efficiency. SiC MOSFETs can reach higher voltage rating with superior switching performance, but they are still expensive compared with comparable Si devices. This makes the conventional topology less attractive compared with its competitor: the newly developed SWISS rectifier (SR) [14]-[17]. SR could also achieve voltage step down function, and the devices also withstand the input-to-line voltages. However, the switching frequency of the most devices in SR is the input fundamental frequency. Therefore, it is easier and more cost-efficient for SR to achieve extreme high efficiency.

In this paper, a circuit improvement is proposed to reduce the voltage stress on transistors in the conventional 3ph-BR topology. The modification splits the freewheeling diode into two diodes in series and connects the input neutral point to the common point of the two diodes. The modulation scheme is 


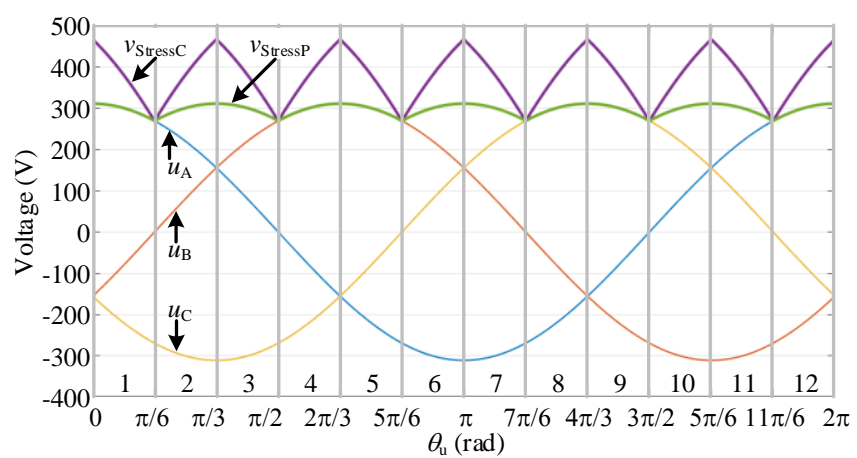

Fig. 2 Sector division of three-phase input voltages $\left(u_{\mathrm{A}}, u_{\mathrm{B}}, u_{\mathrm{C}}\right)$ and the maximum voltage stress on transistors in each sector. $v_{\text {StressC }}$ and $v_{\text {StressP }}$ are for the conventional topology and the proposed topology respectively.

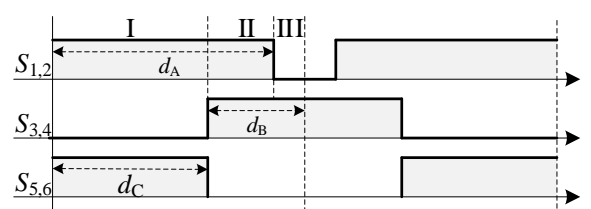

Fig. 3 Switching pattern of the conventional 3ph-BR topology in sector 1

modified accordingly, which turns off all the transistors at the freewheeling stage. With the proposed topology and its modulation scheme, the transistors only need to withstand the input phase voltage instead of the line-to-line voltage. For the $380 \mathrm{~V}$ input applications, the ideal voltage stress on transistors is only $311 \mathrm{~V} .600 \mathrm{~V}$ transistors (e.g. Si MOSFETs) are therefore sufficient for the proposed topology, enabling a more cost-efficient and flexible selection of devices. Besides, the control performance remains the same under unity input power factor.

The rest of this paper is organized as follows. Section II reviews the conventional 3ph-BR topology and presents the voltage stress analysis. Section III introduces the principle of the proposed topology. Section IV presents some discussions. Experimental verification is provided in Section $\mathrm{V}$ and conclusion is drawn in Section VI.

\section{CONVENTIONAL 3PH-BR TOPOLOGY}

\section{A. Modulation Scheme}

Several modulation schemes have been developed for the $3 \mathrm{ph}-\mathrm{BR}$ topology. Among them, the optimized one presented in [7] guarantees minimum switching loss, input and output ripples, and thus is adopted by this paper. In this scheme, the three-phase input voltages are divided into 12 sectors subject to the voltage profile, as shown in Fig. 2. According to the topology symmetry, the following analysis is based on the assumption that input voltages fall into sector 1 . For other sectors, the analysis can be carried out similarly.

In sector 1, the three-phase input voltages are in the sequence of $u_{\mathrm{A}}>0>u_{\mathrm{B}}>u_{\mathrm{C}}$ and their absolute values are in the sequence of $\left|u_{\mathrm{A}}\right|>\left|u_{\mathrm{C}}\right|>\left|u_{\mathrm{B}}\right|$. Therefore, the duty cycles for the three-legs are calculated as [7]:

$$
d_{\mathrm{A}}=K_{\mathrm{d}}\left|u_{\mathrm{A}}\right|, d_{\mathrm{C}}=K_{\mathrm{d}}\left|u_{\mathrm{C}}\right|, d_{\mathrm{B}}=1-d_{\mathrm{C}},
$$

where $K_{\mathrm{d}}$ is expressed as:

$$
K_{\mathrm{d}}=u_{\mathrm{L}}^{*} /\left(u_{\mathrm{A}}^{2}+u_{\mathrm{B}}^{2}+u_{\mathrm{C}}^{2}\right),
$$

where $u_{\mathrm{L}}{ }^{*}$ is the reference value of DC load voltage.

After the duty cycles are obtained, the gate signals can be applied to the transistors according to the switching pattern shown in Fig. 3. The two transistors in each leg share the same gate signals for simplifying the drive logic without affecting the control performance.

\section{B. Voltage Stress Analysis}

As shown in Fig. 3, the switching pattern is divided into 3 stages (I, II, III). At each stage, voltage stresses for devices are illustrated in Table $\mathrm{I}$, where $v_{\mathrm{S} i}$ and $v_{\mathrm{D} i}(i=1,2, \ldots, 6)$ represent the voltage stresses on the transistors and diodes of each input phase leg respectively; $\nu_{\mathrm{DF}}$ represents the voltage stress on the freewheeling diode. Voltages $u_{\mathrm{P}}$ and $u_{\mathrm{N}}$ on the upper and lower DC buses, which are referenced to the neutral point $\mathrm{O}$ of the input filter capacitors, are also listed in Table I to assist the analysis.

Considering the conduction characteristic of all the diodes (including the body diodes of the transistors), the voltage stress analysis is based on the following rules:

1) If $u_{x}>u_{\mathrm{P}}(x=\mathrm{A}, \mathrm{B}, \mathrm{C})$, the corresponding transistor on the upper arm withstands the voltage stress $u_{x}-u_{\mathrm{P}}$ while the diode withstands zero voltage stress. Otherwise, the diode withstands the voltage stress $u_{\mathrm{P}}-u_{x}$ and the transistor withstands zero voltage stress.

2) If $u_{x}<u_{\mathrm{N}}(x=\mathrm{A}, \mathrm{B}, \mathrm{C})$, the corresponding transistor on the lower arm withstands the voltage stress $u_{\mathrm{N}}-u_{x}$ while the diode withstands zero voltage stress. Otherwise, the diode withstands the voltage stress $u_{x}-u_{\mathrm{N}}$ and the transistor withstands zero voltage stress.

3) The freewheeling diode always withstands the output voltage $u_{\mathrm{PN}}$ which is equal to $u_{\mathrm{P}}-u_{\mathrm{N}}$.

Table I Voltage stress analysis for the conventional topology in sector I

\begin{tabular}{cccc}
\hline \hline & Stage I & Stage II & Stage III \\
\hline \hline$u_{\mathrm{P}}$ & $u_{\mathrm{A}}$ & $u_{\mathrm{A}}$ & $u_{\mathrm{B}}$ \\
$u_{\mathrm{N}}$ & $u_{\mathrm{C}}$ & $u_{\mathrm{B}}$ & $u_{\mathrm{B}}$ \\
$v_{\mathrm{S} 1}$ & 0 & 0 & $u_{\mathrm{A}}-u_{\mathrm{B}}$ \\
$v_{\mathrm{S} 2}$ & 0 & 0 & 0 \\
$v_{\mathrm{S} 3}$ & 0 & 0 & 0 \\
$v_{\mathrm{S} 4}$ & 0 & 0 & 0 \\
$v_{\mathrm{S} 5}$ & 0 & 0 & 0 \\
$v_{\mathrm{S} 6}$ & 0 & $u_{\mathrm{B}}-u_{\mathrm{C}}$ & $u_{\mathrm{B}}-u_{\mathrm{C}}$ \\
$v_{\mathrm{D} 1}$ & 0 & 0 & 0 \\
$v_{\mathrm{D} 2}$ & $u_{\mathrm{A}}-u_{\mathrm{C}}$ & $u_{\mathrm{A}}-u_{\mathrm{B}}$ & $u_{\mathrm{A}}-u_{\mathrm{B}}$ \\
$v_{\mathrm{D} 3}$ & $u_{\mathrm{A}}-u_{\mathrm{B}}$ & $u_{\mathrm{A}}-u_{\mathrm{B}}$ & 0 \\
$v_{\mathrm{D} 4}$ & $u_{\mathrm{B}}-u_{\mathrm{C}}$ & 0 & 0 \\
$v_{\mathrm{D} 5}$ & $u_{\mathrm{A}}-u_{\mathrm{C}}$ & $u_{\mathrm{A}}-u_{\mathrm{C}}$ & $u_{\mathrm{B}}-u_{\mathrm{C}}$ \\
$v_{\mathrm{D} 6}$ & 0 & 0 & 0 \\
$v_{\mathrm{DF}}$ & $u_{\mathrm{A}}-u_{\mathrm{C}}$ & $u_{\mathrm{A}}-u_{\mathrm{B}}$ & 0 \\
\hline \hline At & 0 & trans & $S_{5}$
\end{tabular}

At stage I: according to Fig.3, transistors $S_{1}, S_{2}, S_{5}$ and $S_{6}$ are in on-state but only $S_{1}$ and $S_{6}$ conduct the output current $i_{\mathrm{PN}}$ because $u_{\mathrm{A}}>u_{\mathrm{C}}$. The upper bus voltage $u_{\mathrm{P}}$ is equal to $u_{\mathrm{A}}$ while the lower bus voltage $u_{\mathrm{N}}$ is equal to $u_{\mathrm{C}}$. According to the analysis rules, no transistors at this stage withstand voltage stress because of the input voltage sequence $u_{\mathrm{A}}>0>u_{\mathrm{B}}>u_{\mathrm{C}}$. Voltage stresses are withstood by the diodes.

At stage II: similarly, $S_{1}$ and $S_{4}$ conduct the output current, so $u_{\mathrm{P}}$ is equal to $u_{\mathrm{A}}$ and $u_{\mathrm{N}}$ is equal to $u_{\mathrm{B}} . S_{6}$ withstands the voltage stress $u_{\mathrm{B}}-u_{\mathrm{C}}$ which is the minimum value of absolute 


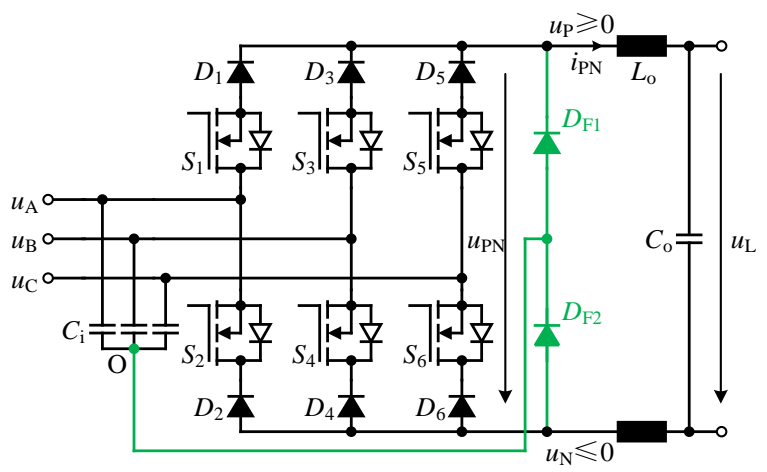

Fig. 4 Proposed topology of three-phase buck rectifier

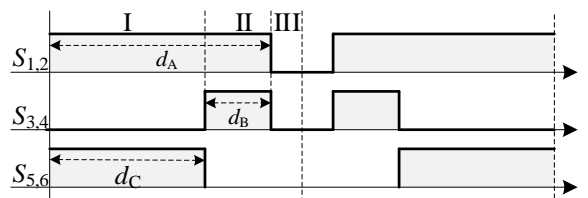

Fig. 5 Switching pattern of the proposed 3ph-BR topology in sector 1

line-to-line input voltages. Other transistors still do not withstand voltage stress.

At stage III: output current flows through the freewheeling diode $D_{\mathrm{F}}$. However, because $S_{3}$ and $S_{4}$ are still in on-state, the bus is clamped to input phase $\mathrm{B}$. Therefore, $u_{\mathrm{P}}$ and $u_{\mathrm{N}}$ are both equal to $u_{\mathrm{B}}$. Transistor $S_{1}$ withstands the voltage stress $u_{\mathrm{A}}{ }^{-} u_{\mathrm{B}}$ which is the middle value of absolute line-to-line input voltages. $S_{6}$ still withstands the voltage stress $u_{\mathrm{B}}-u_{\mathrm{C}}$ while other transistors withstand zero voltage stress.

It can be seen from Table I that diodes can withstand the maximum line-to-line input voltage. However, transistors only need to withstand the middle value of absolute line-to-line input voltages, which happens at the freewheeling stage. The maximum voltage stress $v_{\text {StressC }}$ on transistors of the conventional topology in each sector is plotted in Fig. 2. For the general $380 \mathrm{~V}$ input, the maximum value of $v_{\text {StressC }}$ is about $466 \mathrm{~V}$, less than the amplitude $537 \mathrm{~V}$ of input line-to-line voltages. Nevertheless, this is only true for the optimized switching pattern shown in Fig. 3. If the input phase with minimum voltage (e.g. phase $\mathrm{C}$ in sector 1 ) is clamped to the DC bus at stage III, the maximum value of $v_{\text {StressC }}$ will be $537 \mathrm{~V}$. That means if the wrong gate signals are applied to transistors or gate signals are missing, they could still withstand the maximum input line-to-line voltage. Therefore, for reliability, the voltage rating of switching devices should be selected based on the amplitude of input line-to-line voltage plus additional margin, considering the worst case. For the $380 \mathrm{~V}$ input, $900 \mathrm{~V}$ or $1200 \mathrm{~V}$ transistors are applicable but not those under $650 \mathrm{~V}$.

\section{PROPOSED 3PH-BR TOPOLOGY}

To reduce the voltage stress on transistors, an improved topology is proposed, as shown in Fig. 4. Compared with the conventional topology, the modification is simple, as only the freewheeling diode is split into two diodes $\left(D_{\mathrm{F} 1}\right.$ and $\left.D_{\mathrm{F} 2}\right)$ in series and the neutral point $\mathrm{O}$ of input filter capacitors is connected to the common point of $D_{\mathrm{F} 1}$ and $D_{\mathrm{F} 2}$.

The principle of the proposed topology to reduce the voltage stress on transistors is quite straightforward. According to Fig.

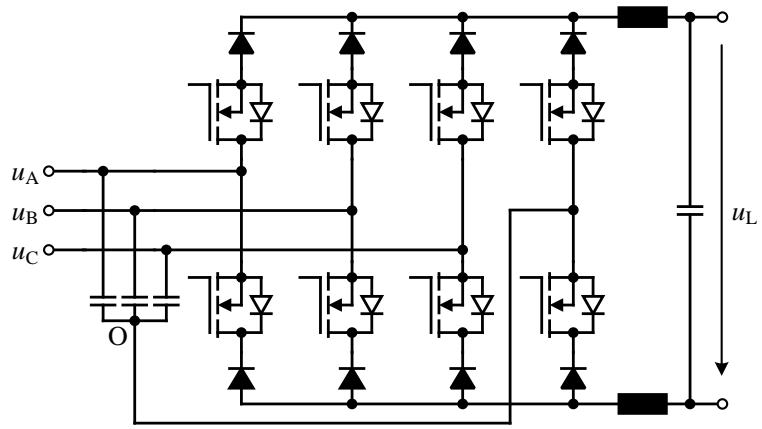

Fig. 6 Topology of the three-phase four-pole buck rectifier [18]

4 , the voltage $u_{\mathrm{P}}$ at bus $\mathrm{P}$ referenced to point $\mathrm{O}$ must be positive, and $u_{\mathrm{N}}$ at bus $\mathrm{N}$ must be negative. Therefore, according to the analysis rules 1) and 2) presented in Section II Part B, the voltage stress on each transistor must be less than the absolute value of phase voltage. It means that the reduction of voltage stress is guaranteed by the circuit itself and is not affected by the modulation scheme.

To generate sinusoidal input current and constant output voltage, the proposed topology needs to adopt the modified switching pattern shown in Fig. 5, which differs from the conventional topology at the freewheeling stage where all transistors are turned off. The duty cycles for each phase are:

$$
d_{\mathrm{A}}=K_{\mathrm{d}}\left|u_{\mathrm{A}}\right|, d_{\mathrm{C}}=K_{\mathrm{d}}\left|u_{\mathrm{C}}\right|, d_{\mathrm{B}}=K_{\mathrm{d}}\left|u_{\mathrm{B}}\right| \text {. }
$$

It can be seen from (1) and (3) that the duty cycle for phase B is changed.

\begin{tabular}{|c|c|c|c|}
\hline & Stage I & Stage II & Stage III \\
\hline$u_{\mathrm{P}}$ & $u_{\mathrm{A}}$ & $u_{\mathrm{A}}$ & 0 \\
\hline$u_{\mathrm{N}}$ & $u_{\mathrm{C}}$ & $u_{\mathrm{B}}$ & 0 \\
\hline$v_{\mathrm{S} 1}$ & 0 & 0 & $u_{\mathrm{A}}$ \\
\hline$v_{\mathrm{S} 2}$ & 0 & 0 & 0 \\
\hline$v_{\mathrm{S} 3}$ & 0 & 0 & 0 \\
\hline$v_{\mathrm{S} 4}$ & 0 & 0 & $-u_{\mathrm{B}}$ \\
\hline$v_{\mathrm{S} 5}$ & 0 & 0 & 0 \\
\hline$v_{\mathrm{S} 6}$ & 0 & $u_{\mathrm{B}}-u_{\mathrm{C}}$ & $-u_{\mathrm{C}}$ \\
\hline$v_{\mathrm{D} 1}$ & 0 & 0 & 0 \\
\hline$v_{\mathrm{D} 2}$ & $u_{\mathrm{A}}-u_{\mathrm{C}}$ & $u_{\mathrm{A}}-u_{\mathrm{B}}$ & $u_{\mathrm{A}}$ \\
\hline$v_{\mathrm{D} 3}$ & $u_{\mathrm{A}}-u_{\mathrm{B}}$ & $u_{\mathrm{A}}-u_{\mathrm{B}}$ & $-u_{\mathrm{B}}$ \\
\hline$v_{\mathrm{D} 4}$ & $u_{\mathrm{B}}-u_{\mathrm{C}}$ & 0 & 0 \\
\hline$v_{\mathrm{D} 5}$ & $u_{\mathrm{A}}-u_{\mathrm{C}}$ & $u_{\mathrm{A}}-u_{\mathrm{C}}$ & $-u_{\mathrm{C}}$ \\
\hline$v_{\mathrm{D} 6}$ & 0 & 0 & 0 \\
\hline$v_{\mathrm{DF} 1}$ & $u_{\mathrm{A}}$ & $u_{\mathrm{A}}$ & 0 \\
\hline$v_{\mathrm{DF} 2}$ & $-u_{\mathrm{C}}$ & $-u_{\mathrm{B}}$ & 0 \\
\hline
\end{tabular}

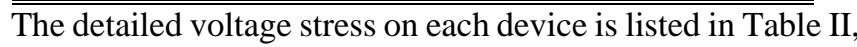
where the differences with Table I have been highlighted in bold and green. Comparing Table I and Table II, it can be found that:

1) At stage I and II, voltage stresses on transistors and their serial diodes remain the same. The voltage stress on the freewheeling diode in the conventional topology is distributed on the two diodes in the proposed topology, but the total voltage stress does not change. Each freewheeling diode withstands voltage stress no larger than the phase voltage.

2) At stage II, the voltage stress on $S_{6}$ is $u_{\mathrm{B}}-u_{\mathrm{C}}$, which is less than $u_{\mathrm{A}}$ according to the input voltage profile in sector I.

3) At stage III, the voltage stress distribution is quite different. For the proposed topology, each leg has one transistor and diode withstanding the corresponding input phase voltage. No 


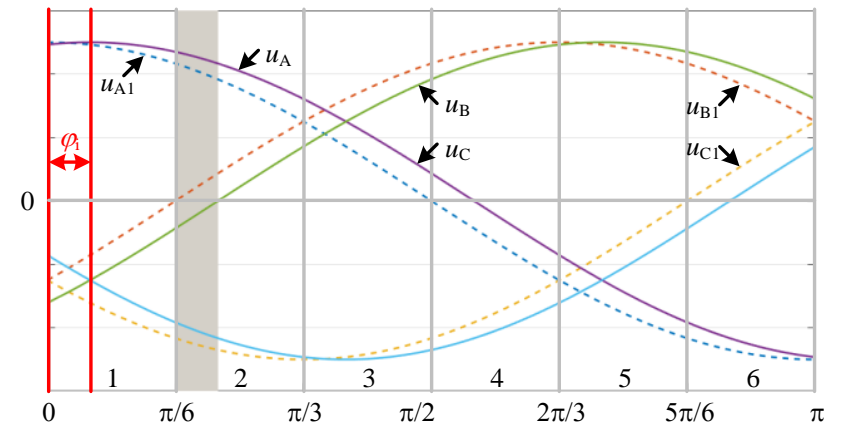

Fig. 7 Modulation signals $\left(u_{\mathrm{A} 1}, u_{\mathrm{B} 1}\right.$, and $\left.u_{\mathrm{C} 1}\right)$ with a displacement angle $\varphi_{1}$. The shadowed part in sector 2 shows the area that the proposed topology loses control.

line-to-line voltage is withstood by any device. In particular, $v_{\mathrm{S} 1}$ and $v_{\mathrm{D} 2}$ withstand the voltage stress $u_{\mathrm{A}}$ which is the maximum input phase voltage.

To sum up, transistors of the proposed topology only need to withstand the input phase voltage instead of the line-to-line voltage. The maximum voltage stress $v_{\text {StressP }}$ on transistors in each sector is also plotted in Fig. 2. For the general 380V input, the maximum value of $v_{\text {StressP }}$ is only the amplitude of phase voltage, which is $311 \mathrm{~V}$ and thus is much smaller than $v_{\text {StressP. }}$ More importantly, there are much more types of low-cost high-performance transistors (e.g. 600V MOSFETs) that can thereby be selected to construct the hardware.

It can also be found from Table I and II that the proposed topology does not change the output voltage $u_{\mathrm{PN}}$ which is equal to $u_{\mathrm{P}}-u_{\mathrm{N}}$, and thus the control performance is not affected. Besides, the only function of the additional connection is to clamp the voltage on each transistor to less than the input phase voltage and there is no current flowing through it to the input filter capacitors. Therefore, no common-mode component will be imposed on the input voltages. Voltages on the input filter capacitors are exactly the same with the conventional topology and are also not affected by the additional connection. For both the conventional and proposed topologies, the input filter capacitors should be selected according to the rated power of the converter, so that the voltage ripple on the capacitors would not affect the voltage stress significantly. Anyhow, the proposed topology always reduces the voltage stress on transistors to the input phase voltage, which is the major benefit the additional connection brings.

It should be noted herein that a similar topology, designated as the four-pole rectifier as shown in Fig. 6, was proposed two decades ago [18]. The same version with thyristors was even earlier. In this topology, the neutral point of input filter capacitors is connected to the fourth leg composed of controlled transistors and diodes. The primary goal of this topology is to reduce the input current harmonics and output voltage ripple with the multilevel modulation scheme. Although the proposed modulation scheme can also be applied to this topology so as to reduce the voltage stress on transistors, selection of the transistor voltage rating still has to be based on the input line-to-line voltages instead of phase voltages in case of missing gate signals of the fourth leg. On the contrary, the voltage stress reduction in the proposed topology is guaranteed by the hardware connection, not affected by the modulation scheme. In addition, the primary goal of splitting freewheeling diodes is to reduce the voltage stress, not to realize the multilevel operation though it does have the capability.

\section{DISCUSSIONS}

\section{A. Influence on the Input Displacement Angle}

For 3ph-BR, the input filter capacitors consume some reactive power, degrading the input power factor. In some cases, the 3ph-BR may need to compensate such reactive power. For traditional topology, this goal can be realized by applying new modulation signals $\left(u_{\mathrm{A} 1}, u_{\mathrm{B} 1}, u_{\mathrm{C} 1}\right)$ with a displacement angle $\varphi_{1}$ referenced to the input voltages $\left(u_{\mathrm{A}}, u_{\mathrm{B}}, u_{\mathrm{C}}\right)$, as shown in Fig. 7.

However, this goal cannot be realized by the proposed topology. As shown in Fig. 4, the voltages $u_{\mathrm{P}}$ and $u_{\mathrm{N}}$ on the upper and lower buses of the proposed topology must be positive and negative respectively, due to the connection of the freewheeling diodes. As a result, the proposed topology must impose positive phase voltages on the upper bus and negative phase voltages on the lower bus. If the new modulation signals are applied to the proposed topology, the converter cannot behave as expected in some phase angle range. For the example shown in Fig. 7, when the phase angle of the new modulation signals fall into the shadowed area in sector 2, the topology will try to impose negative voltage $u_{\mathrm{B}}$ on the upper bus. However, the actual device conducting the DC bus current on the upper bus will be $D_{\mathrm{F} 1}$, instead of the expected transistor $S_{\mathrm{BP}}$. Consequently, distortions will present in the input current of phase B. The width of this area is just equal to the displacement angle $\varphi_{1}$.

Therefore, the proposed topology and the modulation scheme can only generate high-quality input and output currents under zero input displacement angle. However, this drawback is minor as the displacement angle is always set to zero in practice. According to the study of Prof. Kolar's group from ETH [1], the DC output voltage of the buck rectifier satisfies

$$
U_{\mathrm{PN}} \leq \sqrt{\frac{3}{2}} U_{\mathrm{N}, \mathrm{ll}, \mathrm{rms}} \cos \left(\varphi_{\mathrm{i}}\right)
$$

where $U_{\mathrm{PN}}$ is the average DC output voltage; $U_{\mathrm{N}, \mathrm{ll}, \mathrm{rms}}$ is the RMS value of the input line-to-line voltages. It shows that the maximum voltage utilization ratio of the converter is proportional to the cosine of the displacement angle. To obtain wide control range of output voltage, the input displacement angle has to be limited to small values [1]. Actually, the input displacement angle is always set to zero in practice, which is true for both the conventional and proposed topologies. Therefore, the aforementioned drawback is acceptable, especially considering its advantage of reducing the voltage stresses on transistors significantly. In this case, the actual input power factor is not exactly unity resulting from the reactive power consumed by the filter, but would be quite close to unity (usually larger than 0.99) as the input filter should be always selected appropriately according to the rated power.

It should be noted that, the additional displacement angle only affect the power quality, but not the maximum voltage stress on transistors. It can be known from Section III that the maximum voltage stress on transistors will not exceed the amplitude of input voltages, which is determined by the hardware connection of the devices and is not affected by any modulation scheme. 


\section{B. Performance under Disturbed Input Voltages}

In practice, the three-phase input voltages may be distorted and/or unbalanced due to the nonlinear and unbalanced load in the power grid. The practical connection of the input supply and the proposed 3ph-BR topology is shown in Fig. 8, where $u_{\mathrm{A}}{ }^{\prime}, u_{\mathrm{B}}{ }^{\prime}$, and $u_{\mathrm{C}}{ }^{\prime}$ are the real supply voltages and $\mathrm{O}^{\prime}$ is their neutral point. In this case, the three-phase voltages $u_{\mathrm{A}}, u_{\mathrm{B}}$, and $u_{\mathrm{C}}$ on the input filter capacitor referenced to their neutral point $O$ are not equal to the supply voltages, satisfying

$$
\left\{\begin{array}{l}
u_{\mathrm{A}}=u_{\mathrm{A}}{ }^{\prime}-u_{\mathrm{OO}^{\prime}} \\
u_{\mathrm{B}}=u_{\mathrm{B}}{ }^{\prime}-u_{\mathrm{OO}^{\prime}}, \\
u_{\mathrm{C}}=u_{\mathrm{C}}{ }^{\prime}-u_{\mathrm{OO}^{\prime}}
\end{array}\right.
$$

where $u_{\mathrm{OO}}$ is the voltage on point $\mathrm{O}$ referenced to the supply neutral point $\mathrm{O}^{\prime}$. $u_{\mathrm{OO}}$ represents the common-mode component in the three-phase input voltages:

$$
u_{\mathrm{OO}}=\left(u_{\mathrm{A}}{ }^{\prime}+u_{\mathrm{B}}{ }^{\prime}+u_{\mathrm{C}}{ }^{\prime}\right) / 3 \text {. }
$$

With the substitution of (2) into (3), the actual output voltage $u_{\mathrm{PN}}$ on the DC bus when $u_{\mathrm{A}}, u_{\mathrm{B}}$, and $u_{\mathrm{C}}$ fall into sector $\mathrm{I}$ is expressed as:

$$
u_{\mathrm{PN}}=u_{\mathrm{P}}-u_{\mathrm{N}}=d_{\mathrm{A}} u_{\mathrm{A}}-\left(d_{\mathrm{B}} u_{\mathrm{B}}+d_{\mathrm{C}} u_{\mathrm{C}}\right)=u_{\mathrm{L}}^{*} \text {. }
$$

Therefore, with the proposed modulation scheme, the actual output voltage is always equal to its reference, regardless of the common-mode component or the disturbances of distortions and unbalance in the actual supply voltages. This can also be found from the comparison between the two topologies. The output voltages at three stages of the switching pattern are all the same in the two topologies. It is well acknowledged that the conventional 3ph-BR topology with the appropriate modulation scheme has the immunity to input disturbances. Therefore, the proposed topology also has this capability.

According to the presentation in Section III, the transistors only need to withstand the phase voltages $u_{\mathrm{A}}, u_{\mathrm{B}}$, and $u_{\mathrm{C}}$ on the filter capacitors rather than the actual supply voltages $u_{\mathrm{A}}{ }^{\prime}, u_{\mathrm{B}}{ }^{\prime}$, and $u_{\mathrm{C}^{\prime}}$. This means that the common-mode voltage $u_{\mathrm{OO}}$ does not influence the voltages stresses on devices and thus is omitted in this paper. The distortions and unbalance in input voltages increase the instantaneous value of the capacitor voltages and further increase the voltage stress, which should be considered in the selection of devices, just the same with the conventional topology. Nevertheless, $600 \mathrm{~V}$ transistors are still able to tolerant up to $29 \%$ increase from the general $380 \mathrm{~V}$ (L-L RMS) input voltages, with $50 \%$ additional margin.

\section{Conduction and Switching Losses}

\section{1) Conduction Loss}

It is clear from the proposed topology that the conduction loss is increased since two diodes are on the current path at the freewheeling stage. However, the impact is slight as the conduction loss of the freewheeling diodes usually accounts for a small part of the total losses [5], if the voltage utilization ratio is high. Moreover, the freewheeling diodes only need to withstand the input phase voltages instead of the line-to-line voltages, as illustrated in Table II. Therefore, for the general $380 \mathrm{~V}$ input applications, the conventional topology needs to adopt $1200 \mathrm{~V}$ freewheeling diode while the proposed topology only needs to adopt $600 \mathrm{~V}$ freewheeling diodes. Moreover, it is

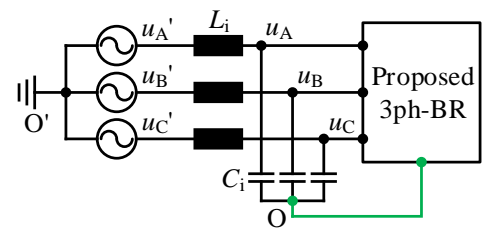

Fig. 8 Connection of the practical supply and the proposed 3ph-BR

possible to use low-cost MOSFETs in parallel to replace the freewheeling diodes, so as to reduce the conduction loss.

\section{2) Switching Loss}

As shown in Fig. 5, the proposed topology with the associated modulation scheme requires more switching actions during the transition from stage II to stage III. However, the total switching loss is actually decreased, benefiting from the reduction of voltage stress.

Table III Transition from stage II to stage III in sector I

\begin{tabular}{ccc|cc}
\hline \hline \multirow{2}{*}{ Devices } & \multicolumn{2}{c|}{ Conventional Topology } & \multicolumn{2}{c}{ Proposed Topology } \\
\cline { 2 - 5 } & $\bar{v} i$ & $\Delta v$ & $\bar{v}$ & $\Delta v$ \\
\hline \hline$S_{1}$ & $\left(u_{\mathrm{A}}-u_{\mathrm{B}}\right) i_{\mathrm{PN}}$ & $u_{\mathrm{A}}-u_{\mathrm{B}}$ & $u_{\mathrm{A}} i_{\mathrm{PN}}$ & $u_{\mathrm{A}}$ \\
$S_{4}$ & 0 & 0 & $-u_{\mathrm{B}} i_{\mathrm{PN}}$ & $-u_{\mathrm{B}}$ \\
$S_{6}$ & 0 & 0 & 0 & $-u_{\mathrm{B}}$ \\
$D_{2}$ & 0 & 0 & 0 & $-u_{\mathrm{B}}$ \\
$D_{3}$ & 0 & $u_{\mathrm{A}}-u_{\mathrm{B}}$ & 0 & $u_{\mathrm{A}}$ \\
$D_{5}$ & 0 & $u_{\mathrm{A}}-u_{\mathrm{B}}$ & 0 & $u_{\mathrm{A}}$ \\
$D_{\mathrm{F}}$ & $\left(u_{\mathrm{A}}-u_{\mathrm{B}}\right) i_{\mathrm{PN}}$ & $u_{\mathrm{A}}-u_{\mathrm{B}}$ & --- & ---- \\
$D_{\mathrm{F} 1}$ & --- & --- & $u_{\mathrm{A}} i_{\mathrm{PN}}$ & $u_{\mathrm{A}}$ \\
$D_{\mathrm{F} 2}$ & --- & --- & $-u_{\mathrm{B}} i_{\mathrm{PN}}$ & $-u_{\mathrm{B}}$ \\
Total & $2\left(u_{\mathrm{A}}-u_{\mathrm{B}}\right) i_{\mathrm{PN}}$ & $4\left(u_{\mathrm{A}}-u_{\mathrm{B}}\right)$ & $2\left(u_{\mathrm{A}}-u_{\mathrm{B}}\right) i_{\mathrm{PN}}$ & $4\left(u_{\mathrm{A}}-u_{\mathrm{B}}\right)$ \\
\hline \hline
\end{tabular}

According to [19], the switching loss $p_{\text {sw }}$ for one device is mainly composed of two parts. The first part is caused by the cross-over of the voltage stress and the current stress. The second part is the loss caused by charging and discharging the output capacitance. Generally, $p_{\mathrm{sw}}$ can be expressed as

$$
p_{\text {sw }}=k_{1}-\overrightarrow{v i}+k_{2}(\Delta v)^{2}
$$

where $\bar{v}$ and $i$ are the average voltage stress and conducted current during the transition; $\Delta v$ is the absolute change of the voltage stresses between two states.

By comparing Table I and Table II, it can be found that the voltage stress and the conducted current during the transition from stage I to stage II are all the same for the topologies, but are different during the transition from stage II to stage III. The differences are listed in Table III. At stage II, devices $S_{1}, D_{1}, S_{4}$, and $D_{4}$ conduct current. At stage III, the freewheeling diodes conduct current. Therefore, only these devices generate the cross-over switching loss. It can be seen from Table III that the two topologies generate the same total of $\overline{v i}$. As a result, for the first part in (8), the two topologies are the same. It can also be seen that the sum of $\Delta v$ are the same for the two topologies. However, as the second part in (8) is proportional to the square of $\Delta v$, the proposed topology generates smaller loss related to this part, according to the Cauchy-Schwarz inequality. In addition, it can also be known that the switching loss distribution in the proposed topology is more balanced, since more devices share the switching loss.

To sum up, the conduction loss in the proposed topology is slightly increased, but it is compromised by the decreased switching loss, if the same devices are adopted. However, the proposed topology enables the adoption of low-cost 
(a)

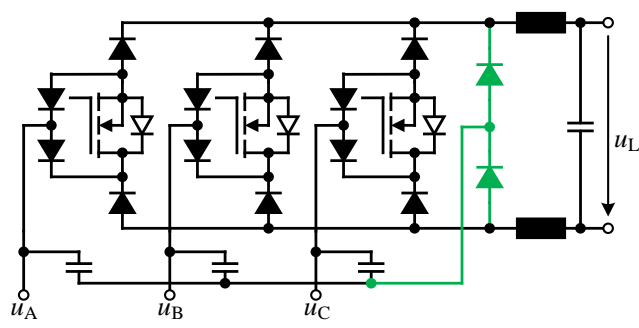

(b)

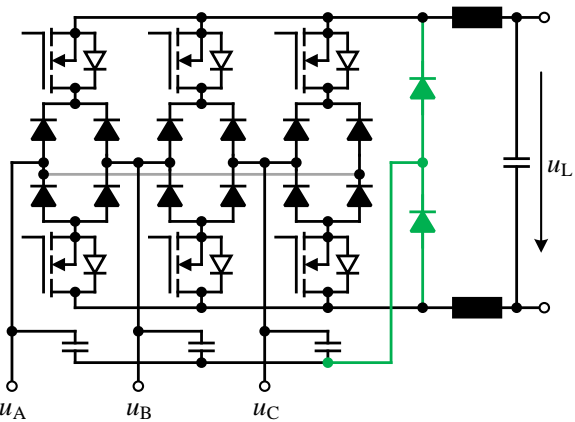

Fig. 9 Extensions of the proposed improvement to other three-phase buck topologies: (a) the improved three-switch 3ph-BR topology; (b) the improved 3ph-BR topology with delta input connection.

high-performance devices, so as to reduce both the conduction and switching losses. Therefore, it is easier and more cost-efficient to achieve higher efficiency, especially for applications requiring high switching frequency.

\section{Extension to Other 3ph-BR Topologies}

The proposed modification can be easily extended to the three-switch 3ph-BR topology and the one with delta input connection presented in [12]. The improved topologies are shown in Fig. 9, of which the freewheeling diode is split into two diodes in series and the neutral point of input filter capacitors is connected to the common point of the two diodes. The modulation scheme needs to be modified accordingly. With the modification, transistors in these topologies also withstand the input phase voltages instead of the line-to-line voltages, reducing the voltage stress significantly. $600 \mathrm{~V}$ transistors are also sufficient for these improved topologies to work under the general $380 \mathrm{~V}$ input.

The topologies discussed in this paper are all unidirectional. If bidirectional power flow is required, the diodes in these topologies can be replaced with transistors with the same voltage rating, while the proposed improvement is still applicable to the transistors on the forward current path.

\section{EXPERIMENTAL VERIFICATION}

\section{A. Experimental Prototype}

In order to verify the effectiveness of the proposed topology, a prototype is constructed, which is presented in Fig. 10. The prototype parameters are listed in Table IV. In particular, the transistors used are MOSFETs with rated voltage of $600 \mathrm{~V}$. The two freewheeling diodes are also rated at $600 \mathrm{~V}$. As all the devices has high switching performance, the sampling frequency is set $60 \mathrm{kHz}$, and thus a small input filter is adequate to attenuate the high frequency harmonics. A passive resistor of $41.6 \Omega$ serves as the load.

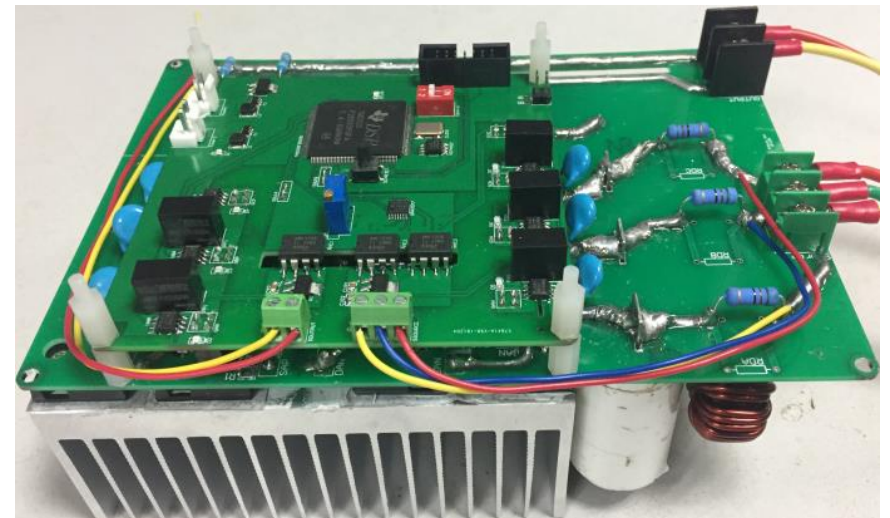

Fig. 10 Experimental prototype of the proposed three-phase buck rectifier

Table IV Prototype Parameters

\begin{tabular}{|c|c|}
\hline Term & Specification \\
\hline Diodes $D_{i}$ & 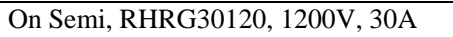 \\
\hline MOSFETs $S_{i}$ & Rohm, R6030ENZ1C9, 600V, $130 \mathrm{~m} \Omega$ \\
\hline Diodes $D_{\mathrm{F} 1}, D_{\mathrm{F} 2}$ & Vishay, VS-EPU3006-N3, 600V, 30A \\
\hline Sampling Frequency $f_{\mathrm{s}}$ & $60 \mathrm{kHz}$ \\
\hline Input Filter Inductor $L_{\mathrm{i}}$ & $100 \mu \mathrm{H}$ \\
\hline Input Filter Capacitor $C_{\mathrm{i}}$ & $5 \mu \mathrm{F}$ \\
\hline Filter Damping Resistor $R_{\mathrm{d}}$ & $51 \Omega$ \\
\hline Output Filter Inductor $L_{\mathrm{o}}$ & $330 \mu \mathrm{H}$ \\
\hline Output Filter Capacitor $C_{\mathrm{o}}$ & $100 \mu \mathrm{F}$ \\
\hline Load Resistor $R_{\mathrm{L}}$ & $41.6 \Omega$ \\
\hline
\end{tabular}

\section{B. Case I: Comparison with Conventional Topology}

The proposed topology is firstly evaluated under sinusoidal and balanced input voltages of $380 \mathrm{~V} / 50 \mathrm{~Hz}$ (line-to-line RMS). The output voltage reference is $400 \mathrm{~V}$. The experimental result is shown in Fig. 11(a), which proves that the proposed topology can obtain sinusoidal input current and constant output voltage. The waveform of the voltage stress $v_{\mathrm{S} 1}$ on the transistor $S_{1}$ shows that it only need to withstand the input phase voltage instead of the line-to-line voltage. Even if the non-ideal switching behavior of power devices increases the voltage stress a bit, no voltage stress on $S_{1}$ larger than $450 \mathrm{~V}$ is observed in experiments. Therefore, $600 \mathrm{~V}$ transistors are sufficient for the proposed topology to work reliably under the general $380 \mathrm{~V} / 50 \mathrm{~Hz}$ input.

On the same prototype, the conventional topology is also evaluated comparatively. In this case, the input neutral point is disconnected from the freewheeling diodes. For safety issue, three-phase input voltages are reduced by half to $190 \mathrm{~V}$ and the output voltage reference is reduced to $200 \mathrm{~V}$ accordingly. The experimental result is shown in Fig. 11(b). It is found that the maximum value of voltage stress on transistor $S_{1}$ is about $290 \mathrm{~V}$. It can be deduced that the voltage stress will increase to over $580 \mathrm{~V}$ with $380 \mathrm{~V}$ input. Therefore, $900 \mathrm{~V}$ or $1200 \mathrm{~V}$ transistors are necessary for the conventional topology with $380 \mathrm{~V}$ input and $600 \mathrm{~V}$ ones are not applicable.

The efficiencies of the two topologies under different input voltages and output voltages are shown in Fig. 12. For fare comparison, the efficiencies are firstly measured under $190 \mathrm{~V}$ input voltage. It can be seen that the efficiencies of the two topologies are quite close in this case. For the proposed topology working under $380 \mathrm{~V}$ input, the converter efficiency is improved when the output voltage increases. The maximum efficiency is about $98.1 \%$. It should be noted that the primary goal of this prototype is to verify the principle of the proposed 


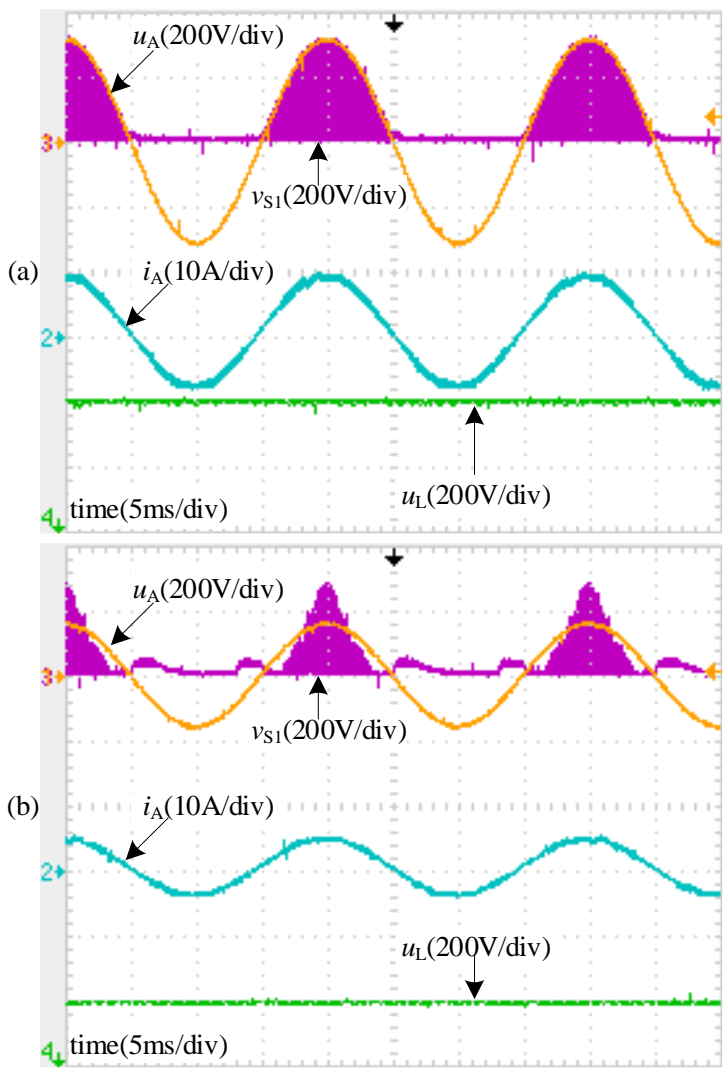

Fig. 11 Experimental results in Case I: (a) with the proposed topology, three-phase input voltages are $380 \mathrm{~V}$ (line-to-line RMS) and output voltage is $400 \mathrm{~V}$; (b) with the conventional topology, input voltages are reduced to $190 \mathrm{~V}$ and output voltage is $200 \mathrm{~V}$ for safety of the prototype. $u_{\mathrm{A}}$ and $i_{\mathrm{A}}$ are the voltage and current of input phase A respectively. $u_{\mathrm{L}}$ is the load voltage. $v_{\mathrm{S} 1}$ is the measured voltage stress on transistor $S_{1}$.

topology. The converter efficiency can be further improved by the optimized design with high-performance devices.

\section{Case II: Performance under Disturbed Supply Voltages}

In this case, the proposed topology is evaluated under input voltage disturbances. The three-phase supply voltages are set unbalanced, of which the RMS values are $240 \mathrm{~V}, 220 \mathrm{~V}$, and $200 \mathrm{~V}$ separately. Each phase voltage contains $5 \% 5^{\text {th }}$ and $5 \%$ $7^{\text {th }}$ harmonics. In addition, common-mode voltage of $100 \mathrm{~V}$ is injected to the supply voltages. The waveforms of the three-phase supply voltages are shown in Fig. 13(a). It can be found that the supply voltages are highly disturbed with large DC bias.

Although the voltage disturbance causes distorted input current as presented in Fig. 13(a), the load voltage keeps constant as shown in Fig. 13(b). Besides, the transistor only needs to withstand the phase voltage on the input filter capacitor, rather than the real supply phase voltage. The common-mode voltage does not affect the voltage stress. Although the voltage distortions and unbalance increase the instantaneous amplitude of the input phase voltages, the adopted $600 \mathrm{~V}$ devices could still work reliably in this case.

Fig. 11, Fig.12 and Fig. 13 under various working conditions also prove that the prototype works safely without being damaged by any overvoltage transient. Therefore, the additional connection is sufficiently robust to reduce the voltage stress on transistors.

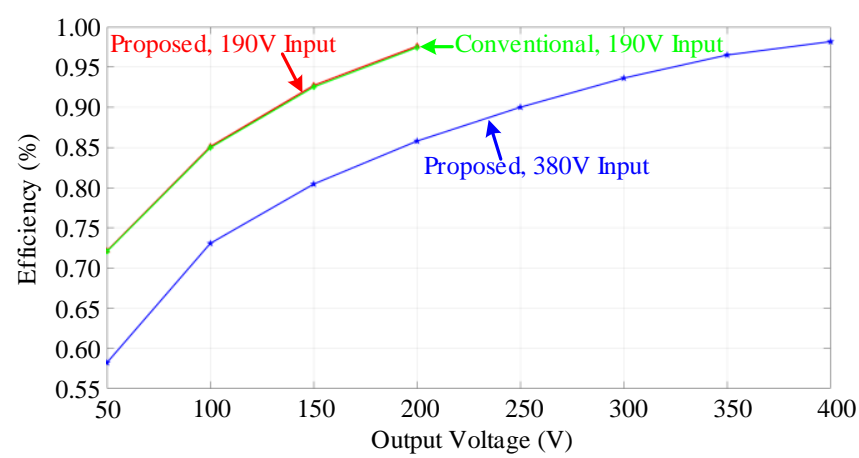

Fig. 12 Efficiency comparison for the conventional and proposed topologies.

\section{CONCLUSION}

It was widely taken for granted that the voltage rating of all the devices in the three-phase buck rectifier should be selected based on the amplitude of input line-to-line voltages. This makes the conventional topology less competitive than other solutions in terms of performance and cost. As demonstrated in this paper, the transistors only need to withstand the input phase voltage, only if the hardware connection is modified slightly. $600 \mathrm{~V}$ transistors, instead of $900 \mathrm{~V}$ or $1200 \mathrm{~V}$ ones required by conventional topology, are sufficient for the proposed topology to work under the general $380 \mathrm{~V}$ (line-to-line RMS voltage) input with almost $100 \%$ safety margin. Therefore, the proposed topology is a very competitive solution to other topologies.

To generate high-quality input and output power, the proposed topology needs to adopt the modified modulation scheme. A drawback of the proposed topology with this scheme is that it has to work under zero input displacement angle, otherwise the input currents may be distorted. Nevertheless, such drawback is minor, as zero input displacement angle is the common operation mode of the three-phase buck rectifier.

In the future, paralleling low-cost MOSFETs to explore the extreme efficiency of the proposed topology will be an interesting topic.

\section{REFERENCES}

[1] J. W. Kolar and T. Friedli, "The Essence of Three-Phase PFC Rectifier Systems-Part I," IEEE Transactions on Power Electronics, vol. 28, no. 1, pp. 176-198, Jan. 2013.

[2] T. Friedli, M. Hartmann and J. W. Kolar, "The Essence of Three-Phase PFC Rectifier Systems-Part II," IEEE Transactions on Power Electronics, vol. 29, no. 2, pp. 543-560, Feb. 2014.

[3] A. K. Singh, E. Jeyasankar, P. Das and S. K. Panda, "A Matrix-Based Nonisolated Three-Phase AC-DC Rectifier With Large Step-Down Voltage Gain," IEEE Transactions on Power Electronics, vol. 32, no. 6, pp. 4796-4811, June 2017.

[4] A. Stupar, T. Friedli, J. Minibock and J. W. Kolar, "Towards a 99\% Efficient Three-Phase Buck-Type PFC Rectifier for 400-V DC Distribution Systems," IEEE Transactions on Power Electronics, vol. 27, no. 4, pp. 1732-1744, April 2012.

[5] T. Nussbaumer, M. Baumann and J. W. Kolar, "Comprehensive Design of a Three-Phase Three-Switch Buck-Type PWM Rectifier," IEEE Transactions on Power Electronics, vol. 22, no. 2, pp. 551-562, March 2007.

[6] M. Baumann and J. Kolar, "Comparative evaluation of modulation methods for a three-phase/switch buck power factor corrector concerning the input capacitor voltage ripple," Proc. 32nd IEEE Power Electron. Spec. Conf., Vancouver, Canada, Jun. 2001, vol. 3, pp. 1327-1333.

[7] T. Nussbaumer and J. W. Kolar, "Advanced modulation scheme for three-phase three-switch buck-type PWM rectifier preventing mains current distortion originating from sliding input filter capacitor voltage 
(a)

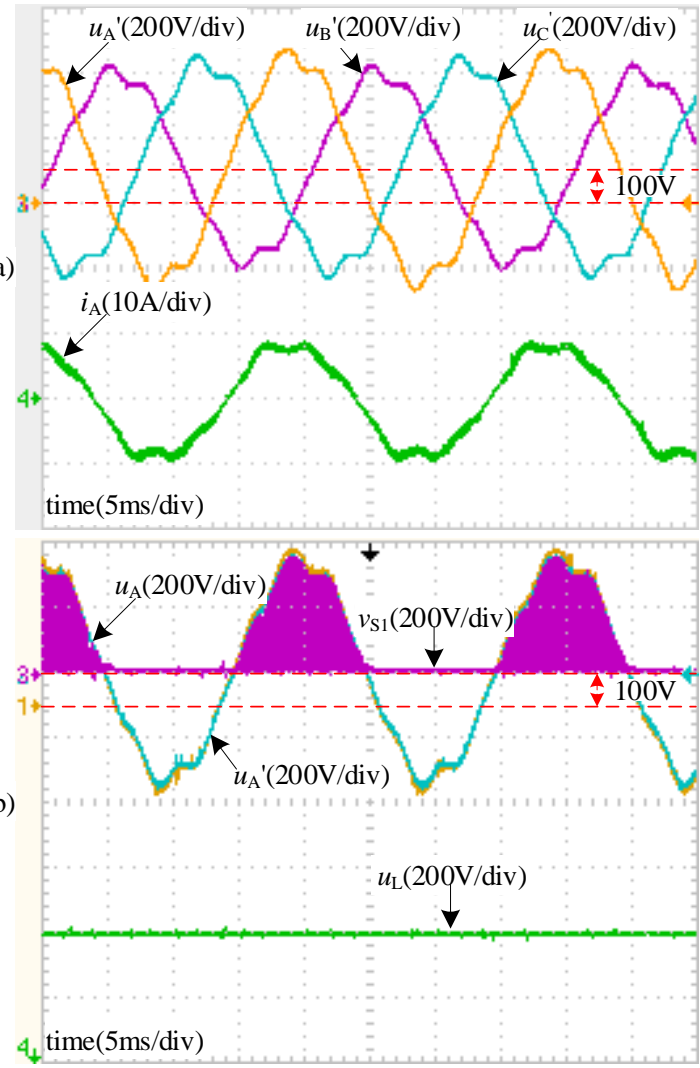

Fig. 13 Experimental results in Case II: (a) the three-phase supply voltages $u_{\mathrm{A}}$, $u_{\mathrm{B}}{ }^{\prime}$ and $u_{\mathrm{C}}{ }^{\prime}$, and the input current $i_{\mathrm{A}} ;$ (b), the source voltage $u_{\mathrm{A}}{ }^{\prime}$, input capacitor voltage $u_{\mathrm{A}}$, voltage stress $v_{\mathrm{S} 1}$ on transistor $S_{1}$, and the load voltage $u_{\mathrm{L}}$.

intersections," IEEE 34th Annual Conference on Power Electronics Specialist, 2003. PESC '03., Acapulco, Mexico, 2003, pp. 1086-1091 vol.3.

[8] B. Chae, Y. Suh and T. Kang, "Carrier based PWM for reduced capacitor voltage ripple in three-phase three-switch buck-type rectifier system," 2017 IEEE Energy Conversion Congress and Exposition (ECCE), Cincinnati, OH, 2017, pp. 4609-4616.

[9] T. Nussbaumer, M. L. Heldwein and J. W. Kolar, "Common mode EMC input filter design for a three-phase buck-type PWM rectifier system," Twenty-First Annual IEEE Applied Power Electronics Conference and Exposition, 2006. APEC '06., Dallas, TX, 2006, pp. 7.

[10] F. Xu, B. Guo, L. M. Tolbert, F. Wang and B. J. Blalock, "An All-SiC Three-Phase Buck Rectifier for High-Efficiency Data Center Power Supplies," IEEE Transactions on Industry Applications, vol. 49, no. 6, pp. 2662-2673, Nov.-Dec. 2013.

[11] B. Guo, F. (Fred). Wang, R. Burgos and E. Aeloiza, "Modulation Scheme Analysis for High-Efficiency Three-Phase Buck-Type Rectifier Considering Different Device Combinations," IEEE Transactions on Power Electronics, vol. 30, no. 9, pp. 4750-4761, Sept. 2015.

[12] B. Guo, F. (Fred). Wang and E. Aeloiza, "A Novel Three-Phase Current Source Rectifier With Delta-Type Input Connection to Reduce the Device Conduction Loss," EEE Transactions on Power Electronics, vol. 31, no. 2, pp. 1074-1084, Feb. 2016.

[13] F. Udrea, G. Deboy and T. Fujihira, "Superjunction Power Devices, History, Development, and Future Prospects," IEEE Transactions on Electron Devices, vol. 64, no. 3, pp. 713-727, March 2017.

[14] T. B. Soeiro, T. Friedli and J. W. Kolar, "Design and Implementation of a Three-Phase Buck-Type Third Harmonic Current Injection PFC Rectifier SR," IEEE Trans. Power Electron., vol. 28, no. 4, pp. 1608-1621, April 2013.

[15] M. Silva, N. Hensgens, J. A. Oliver, P. Alou, O. Garcia, and J. A. Cobos, "Isolated SWISS-forward three-phase rectifier with resonant reset," IEEE Trans. Power Electron., vol. 31, no. 7, pp. 4795-4808, Jul. 2016.

[16] L. Schrittwieser, J. W. Kolar, and T. B. Soeiro, "Novel SWISS Rectifier Modulation Scheme Preventing Input Current Distortions at Sector Boundaries," IEEE Trans. Power Electron., vol. 32, no. 7, pp. 5771-5785, Jul. 2017.
[17] L. Schrittwieser, M. Leibl, M. Haider, F. Thöny, J. W. Kolar and T. B. Soeiro, "99.3\% Efficient Three-Phase Buck-Type All-SiC SWISS Rectifier for DC Distribution Systems," IEEE Trans. Power Electron., vol. 34, no. 1, pp. 126-140, Jan. 2019.

[18] L. S. Slazar, F. H. Zapata and E. F. Wiechmann, "Analysis, design and experimental evaluation of a four-pole PWM rectifier using space vector modulation," IEEE PESC97. Saint Louis, MO, USA, 1997, pp. 484-490 vol.1.

[19] Y. Xiong, S. Sun, H. Jia, P. Shea and Z. John Shen, "New Physical Insights o n Power MOSFET Switching Losses," IEEE Trans. Power Electron., vol. 24, no. 2, pp. 525-531, Feb. 2009.

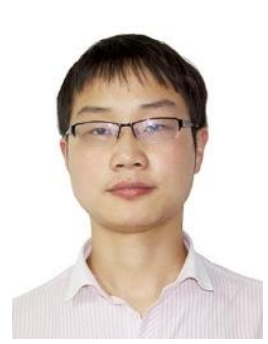

Jiaxing Lei (S'14-M'17) was born in Dazhou, Sichuan Province, China, in 1991. He received his B.Sc. and Ph.D. degree in electrical engineering from the College of Automation Engineering, Nanjing University of Aeronautics and Astronautics, Nanjing, China, in 2012 and 2017, respectively.

From September 2015 to September 2016, he was a visiting researcher at the Power Electronics, Machines and Control Group (PEMC), University of Nottingham, Nottingham, U.K. In 2017, he joined Southeast University, where he has been a lecturer in the School of Electrical Engineering. His research interest is AC-AC converter, mainly matrix converter, and its application in offshore wind energy system, motor drive system, and et al.

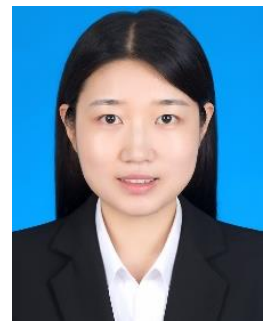

Shuang Feng (M'18) was born in Huaian, Jiangsu Province, China, in 1990. She received her B.Sc. degree in Electrical Engineering from Nanjing University of Aeronautics and Astronautics, Nanjing, China, in 2012. She received her Ph.D. degree in Electrical Engineering from Southeast University, China, in 2017.

She was a visiting researcher in the Department of Electrical and Computer Engineering at Texas A\&M University from 2015 to 2016. Since 2017, she has been a lecturer in the School of Electrical Engineering, Southeast University. Her research interests include power system stability and control and data analysis of phasor measurement unit.

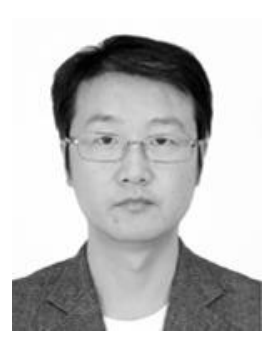

Jianfeng Zhao received the B.S. degree in electrical engineering from Huainan Mining Institute, Anhui, China, in 1995, the M.S. degree in automation from Nanjing University of Aeronautics and Astronautics, Nanjing, China, in 1998, and the Ph.D. degree in electrical engineering from Southeast University, Nanjing, China, in 2001.

In 2001, he joined the Faculty of the School of Electrical Engineering, Southeast University, where he has been a Professor since 2008. He has been teaching and researching in the field of high-power electronics and has been serving as the President of the School of Electrical Engineering in Southeast University since 2014. He has authored more than 80 technical papers. He currently holds 35 Chinese patents. His main research interests are utility applications of power electronics in smart grids, such as solid-state transformers, active filters for power conditioning, flexible ac transmission system devices, multilevel ac motor drivers, and efficient energy utilization.

Dr. Zhao has been a member of the Technical Committee of Standard Voltages, Current Ratings and Frequencies of China since 2010. He has also been a member of the All-China Youth Federation since 2010.

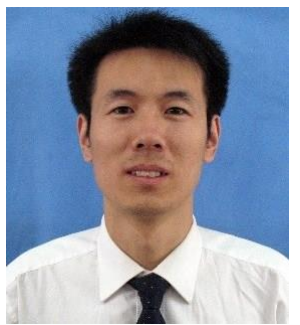

Wu Chen (S'05-M'12) was born in Jiangsu, China, in 1981. He received the B.S., M.S., and $\mathrm{Ph} . \mathrm{D}$. degrees in electrical engineering from Nanjing University of Aeronautics and Astronautics, Nanjing, China, in 2003, 2006, and 2009, respectively. From 2009 to 2010, he was a Senior Research Assistant with the Department of Electronic Engineering, City University of Hong Kong, Kowloon, Hong Kong. From 2010 to 2011, he was a Postdoctoral Researcher with Future Electric Energy Delivery and Management Systems Center, North Carolina 
State University, Raleigh, NC, USA. Since September 2011, he has been an Associate Research Fellow with the School of Electrical Engineering, Southeast University, Nanjing, China, where he has been a Professor since 2016. His research interests include soft-switching converters, power delivery, and power electronic system integration.

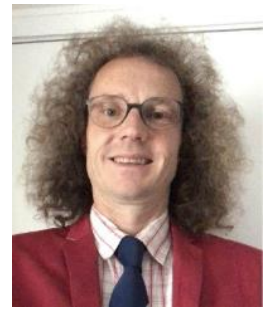

Patrick Wheeler (SM'11) received his BEng [Hons] degree in 1990 from the University of Bristol, UK. He received his $\mathrm{PhD}$ degree in Electrical Engineering for his work on Matrix Converters from the University of Bristol, UK in 1994.

In 1993 he moved to the University of Nottingham and worked as a research assistant in the Department of Electrical and Electronic Engineering. In 1996 he became a Lecturer in the Power Electronics, Machines and Control Group at the University of Nottingham, UK. Since January 2008 he has been a Full Professor in the same research group. He is currently Head of the Department of Electrical and Electronic Engineering at the University of Nottingham and the Li Dak Sum Chair Professor in Electrical and Aerospace Engineering at the University of Nottingham, China. He is a member of the IEEE PELs AdCom and was an IEEE PELs Distinguished Lecturer from 2013 to 2017. He has published 500 academic publications in leading international conferences and journals.

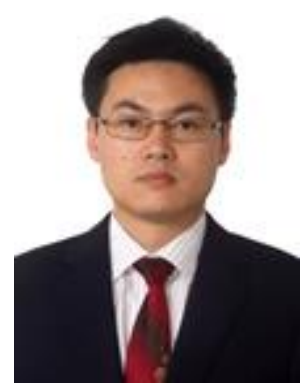

and microgrid.
Mingming Shi was born in Nanjing, Jiangsu Province, China, in 1986. He received the B.S. and $\mathrm{Ph} . \mathrm{D}$. degrees in electrical engineering from the Nanjing University of Aeronautics and Astronautics (NUAA), in 2007 and 2012, respectively.

Since 2012, he joined in State Grid Jiangsu Electric Power Co., LTD. Research Institute (JSEPRI). Now he is the deputy director of New energy \& Distribution Grid department. His research is focusing on DC distributed generation systems, power quality analysis, renewable energy 